\section{PEG-PLA Nanocapsules Containing a Nanobiotechnological Complex of Polyhemoglobin-Tyrosinase for the Depletion of Tyrosine in Melanoma: Preparation and In Vitro Characterisation}

\section{Caroline Fustier and Thomas M.S. Chang*}

Artificial Cells and Organs Research Center, Departments of Physiology, Medicine and Biomedical Engineering, Faculty of Medicine, McGill University, Montreal, Quebec, Canada

\begin{abstract}
Poly (ethylene glycol)-poly (lactic acid) block-copolymer (PEG-PLA) was optimized and characterized using $\mathrm{H}-\mathrm{NMR}$ spectrum and DSC thermogram. This was then used for the preparation of PEG-PLA nanocapsules containing polyhemoglobin-tyrosinase. Transmission electron microscopic and scanning electron microscopic studies showed round and non-aggregated nanocapsules with a PEG halo around each nanocapsule. Dynamic Light Scattering showed that the Z-average diameter was $65.2 \pm 0.5 \mathrm{~nm}$ (mean \pm SEM) and the polydispersity index was $0.262 \pm 0.002$. Factors controlling the diameters included the stirring speed of the reaction mixture and the size of the PLA block in the PEG-PLA copolymer. At the body temperature of $37^{\circ} \mathrm{C}$, free tyrosinase lost all its enzyme activity after 8 hours. However, Polyhemoglobin-tyrosinase nanocapcules retained $80 \%$ of its initial activity after 8 hours. This paper contains the first part of our work on the preparation and in vitro characterisation of PEGPLA Polyhemoglobin-tyrosinase nanocapsules. Preliminary result in rats shows that 1 intravenous injection lowers the systemic tyrosine level to $10-13 \%$ after 5 minutes. The result of the detailed in vitro study and the preliminary animal study in have led to our ongoing detailed animal research to be reported in subsequent papers.
\end{abstract}

Keywords: Melanoma; PEG-PLA nanocapsules; Artificial cells; Tyrosinase; Tyrosine

\section{Introduction}

Melanoma is a fatal skin cancer that is responsible for 48,000 deaths per year in the world $[1,2]$. Surgical excision is the only curative therapy for melanoma at this time [1]. However, in the case of metastases and particularly when they are numerous, surgery is often impossible. Palliative therapies include radiation therapy; chemotherapy and immunotherapy that have severe side effects. Thus there is much interest for the development of new therapeutics for melanoma [2]. Growth of melanoma requires higher concentrations of tyrosine than normal biological cells. Tyrosine is one of the essential amino acids that come from dietary intake, degradation of proteins and hydroxylation of phenylalanine. Meadow's group shows that dietary restriction of tyrosine inhibits the growth of melanoma in animals [3]. However, tyrosine-restricted diet is unpalatable and the diet is not well-tolerated by humans, as it causes nausea, vomiting, and weight loss [3]. Another way of lowering systemic tyrosine levels without the need for a restricted diet is to use enzymes that degrade tyrosine. A candidate for this purpose is tyrosinase which converts tyrosine to L-dopa (L-3,4-dihydroxyphenylalanine) [4]. However, tyrosinase has a very short intravenous half-life and repeated injections can result in immunological problems.

Chang's group used a nanobiotechnological approach to solve this problem. Nanobiotechnology is the assembling of biological molecules into nanodimension complexes of less than 100 nanometer dimension (particle diameter, membrane thickness or tubular diameter). This principle was first reported by his group in the form of nanodimension complexes of hemoglobin with other enzymes or polyhemoglobin-enzymes [5-8]. Recently his group uses this approach to prepare polyhemoglobin-tyrosinase. In the form of polyhemoglobin-tyrosinase the enzyme activity after intravenous injection lasts for 24 hours as compared to $30 \mathrm{mins}$ for the free tyrosine. Polyhemoglobin-tyrosinase inhibits the growth of melanoma in vitro and, when injected intravenously, retards the growth murine B16F10 melanoma in a melanoma mouse model [9]. However, this requires the daily intravenous injection of polyhemolgobin-tyrosinase. In order to solve this need for daily intravenous injection, the present report is to prepare PEG- PLA.

The reasons for using PEG-PLA membrane nanocapsules are as follows.

Polymeric artificial cells are originally of microscopic dimensions in the form of semipermeable microcapsules containing biological material including enzymes for experimental therapy $[7,10,11]$. In the recent years, this has evolved into polymeric artificial cells of nano, micro or macro dimensions for use in nanomedicine and other areas $[12,13]$. In nanomedicine, the original biodegradable PLA microcapsules containing biological materials [14] has been extended to prepare different types of biodegradable polymeric nanocapsules and nanoparticles. Many different methods have been developed for the preparation of PEG-PLA nanocapsules or nanoparticles [15]. Most of the interests are related to their use as carriers for drugs such as lidocaine, procaine hydrochloride, or taxol. This is perhaps due to the fact that many of the methods use solvents such as methylene chloride

${ }^{*}$ Corresponding author: Thomas M.S. Chang, Director, Artificial Cells \& Organs Research Centre, Department of Physiology, Faculty of Medicine, McGill University 3655 Drummond Street, Room 1004, Montreal, Quebec, Canada, Tel: 514-3983512; E-mail: artcell.med@mcgill.ca

Received December 02, 2011; Accepted January 30, 2012; Published February 02, 2012

Citation: Fustier C, Chang TMS (2012) PEG-PLA Nanocapsules Containing a Nanobiotechnological Complex of Polyhemoglobin-Tyrosinase for the Depletion of Tyrosine in Melanoma: Preparation and In Vitro Characterisation. J Nanomedic Biotherapeu Discover 2:103. doi:10.4172/2155-983X.1000103

Copyright: @ 2012 Fustier C, et al. This is an open-access article distributed unde the terms of the Creative Commons Attribution License, which permits unrestricted use, distribution, and reproduction in any medium, provided the original author and source are credited. 
Citation: Fustier C, Chang TMS (2012) PEG-PLA Nanocapsules Containing a Nanobiotechnological Complex of Polyhemoglobin-Tyrosinase for the Depletion of Tyrosine in Melanoma: Preparation and In Vitro Characterisation. J Nanomedic Biotherapeu Discover 2:103. doi:10.4172/2155983X.1000103

Page 2 of 9

that can cause the denaturation of proteins, especially enzymes $[15,16]$ For example, Zambaux et al. [17] reported that encapsulated Protein C only retained $25 \%$ of its activity due to inactivation during encapsulation. They can reduce this inactivation by adding acetone to the organic solvent. Alonso's group encapsulated tetanus toxoid [18] and reported that the stability of tetanus toxoid and the degradation of the nanocapsule was a major problem. Chang's group has carried out much studies to protect the stability of encapsulated protein and enzymes $[7,8,11,12-14]$ including those in nanocapsules $[12,13,19,20]$. We report in this paper, the use of this background to design a nanoencapsulation method that results in the retention of $74.5 \%$ of the initial tyrosinase activity after nanoencapsulation (Figure 1). PEG-PLA nanocapsules containing Polyhemoglobin-enzymes have a much longer circulation time in the circulating blood compared to Polyhemoglobin-enzymes [20]. This first paper is a detail report on the preparation and characterization of PEG-PLA nanocapsules containing polyhemoglobin-tyrosinase. Preliminary result in rats shows that 1 intravenous injection lowers the systemic tyrosine level to $10-13 \%$ after 5 minutes. The result of the detailed in vitro study and the preliminary animal study have led to our ongoing detailed animal research to be reported in subsequent papers

\section{Methods}

\section{Materials}

DL-PLA (M.W. $=6,000$ to $16,000 \mathrm{~g} / \mathrm{mol}$ and M.W. $=15,000$ to $25,000 \mathrm{~g} / \mathrm{mol}$ ) was purchased from Polysciences, Inc (Warrington, Pennsylvania, USA). Tween 20 was obtained from Fisher. L- $\alpha$ Phosphatidylcholine was purchased from Avanti (Alabaster, Alabama, USA). Methoxypolyethylene glycol (M.W. $=5,000 \mathrm{~g} / \mathrm{mol}$ ), tyrosinase from mushrooms (EC 1.14.18.1), glutaraldehyde, L-lysine monohydrochloride and other analytical-grade reagents were obtained from Sigma.

\section{Preparation of polyHb-tyrosinase}

1. To a $50 \mathrm{ml}$ Erlenmeyer flask is added $15 \mathrm{dL}$ of stroma-free hemoglobin $(\mathrm{SFHb})$ with a concentration of $13.3 \mathrm{~g} \mathrm{Hb} / \mathrm{dL}$ and $5 \mathrm{ml}$ of a solution of $24 \mathrm{key} / \mathrm{ml}$ tyrosinase in a $0.1 \mathrm{~mol} / \mathrm{L}$ sodium phosphate buffer $(\mathrm{pH}=7.4)$. The SFHb was prepared by the method described elsewhere [13].

2. Lysine was added at a molar ratio of 7:1 lysine/hemoglobin and the mixture was stirred for one hour at $140 \mathrm{rpm}$ at $4^{\circ} \mathrm{C}$.

3. Cross linking was initiated by the addition of $0.5 \mathrm{M}$ glutaraldehyde at a molar ratio of 16:1 glutaraldehyde/hemoglobin in four equal aliquots every 3 minutes.

4. The stirring was continued for 24 hours at $4^{\circ} \mathrm{C}$. After that, lysine was added at a molar ratio of 200:1 lysine/hemoglobin in order to quench the crosslinking.

5. The PolyHb-tyrosinase was dialyzed overnight with a dialysis membrane at $4^{\circ} \mathrm{C}($ molecular weight cut off $=12-14 \mathrm{kDa})$ against 4 liters of Ringer Lactate solution (for big quantities, a second dialysis of a few hours was performed). It was then passed through sterile $0.45 \mu \mathrm{m}$ syringe filters to remove impurities. All operations (2-5) were carried out at $4^{\circ} \mathrm{C}$ and under nitrogen to prevent methemoglobin formation and the degradation of the enzyme.

6. The PolyHb-tyrosinase was further concentrated to a concentration of 8 to $10 \mathrm{~g} / \mathrm{dL}$. For small quantities $(2 \mathrm{~mL})$, the concentration was performed with $100 \mathrm{kDa}$ Microtone micro concentrators
(Millipore, Billerica, Massachusetts, USA): aliquots of $500 \mu \mathrm{l}$ were centrifuged at $2500 \mathrm{~g}$ for 55 minutes at $4^{\circ} \mathrm{C}$ and the retentate was collected. For bigger quantities $(20 \mathrm{~mL})$, the PolyHb-tyrosinase was concentrated with a Millipore Lab scale TFF system operating with a 100kDa Pellicon XL filter (Millipore). The operation was carried out under nitrogen.

\section{Preparation of PEG-PLA copolymer}

1.5 grams of DL-PLA (M.W. $=6,000$ to $16,000 \mathrm{~g} / \mathrm{mol}$ ) and 0.75 grams of methoxypolyethylene glycol (M.W. $=5,000 \mathrm{~g} / \mathrm{mol}$ ) were placed in a $125 \mathrm{ml}$ Erlenmeyer flask and dried under vacuum overnight in a vacuum oven (Fisher isotemp) at room temperature in the presence of phosphorus pentoxide. They were dissolved in a flask in 7.5 $\mathrm{mL}$ of acetone. The mixture was heated in an oil bath under nitrogen. The acetone evaporated completely in 2 to 3 minutes and the flask was left in the oil bath at $180^{\circ} \mathrm{C}$ for two more hours. $10 \mu \mathrm{L}$ of the catalyst stannous-2-ethylhexanoate were then added and the flask was heated for 3 more hours at $180^{\circ} \mathrm{C}$ under nitrogen. The copolymer solidified slowly at room temperature. It was collected in a vial and stored in a desiccators.

\section{Preparation of tyrosinase nanocapsules}

The nanocapsules were prepared by injecting an organic phase containing the copolymer into an aqueous phase containing Polyhemoglobin-tyrosinase.

1. $90 \mathrm{mg}$ of the PEG-PLA copolymer was dissolved in $3.2 \mathrm{ml}$ of acetone. $20 \mathrm{mg}$ of phosphatidylcholine was dissolved in $1.6 \mathrm{ml}$ of ethanol. These were mixed together and formed the organic phase.

2. The aqueous phase consisted of $10 \mathrm{ml}$ of the PolyHb-tyrosinase previously prepared and $16 \mu \mathrm{L}$ of tween 20

3. The organic phase was injected very slowly through a $26 \mathrm{G}$ needle above the aqueous phase at a rate of $3 \mathrm{ml} / \mathrm{min}$ under magnetic stirring with a Term-o-swirl stirrer (Precision Scientific) and a speed set at 6 at $4^{\circ} \mathrm{C}$. The suspension was kept stirring for 15 minutes at $4^{\circ} \mathrm{C}$, after which $150 \mu \mathrm{L}$ of tween 20 was added to prevent aggregation.

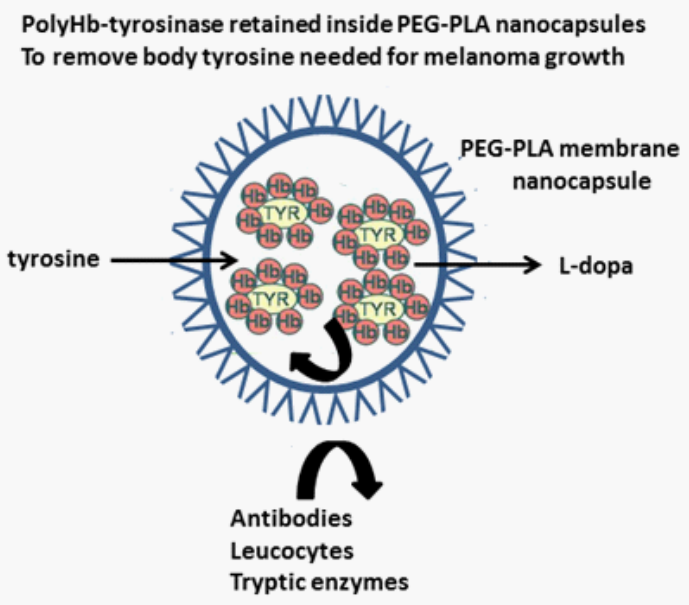

Figure1: Schematic representation of PEG-PLA nanocapsules containing Polyhemoglobin-tyrosinase (PolyHb-TYR). PolyHb-TYR retained inside is separated and protected from external antibodies, leucocytes and tryptic enzymes. Smaller molecules like tyrosine can equilibrate rapidly into the nanocapsules to be removed and converted by PolyHb-TYR into L-dopa that can diffuse out. 
Citation: Fustier C, Chang TMS (2012) PEG-PLA Nanocapsules Containing a Nanobiotechnological Complex of Polyhemoglobin-Tyrosinase for the Depletion of Tyrosine in Melanoma: Preparation and In Vitro Characterisation. J Nanomedic Biotherapeu Discover 2:103. doi:10.4172/2155983X.1000103

Page 3 of 9

4. The solvents were removed by evaporation with a rotary evaporator with adjustable vacuum created by a Gem 1.0 vacuum pump (Gardner Denver Welch Vacuum Technology, Inc, Skokie, Illinois).

5. The nanocapsules were further washed by addition of $15 \mathrm{ml}$ of saline and concentration with a $50 \mathrm{ml}$ Millipore stirred cells device operating with a Biomax PB Polyethersulfone membrane (Millipore, molecular weight cut off $=500 \mathrm{kDa}$ ) and a pressure of $69 \mathrm{kPa}$.

All operations (except 4: evaporation) were carried out at $4^{\circ} \mathrm{Cand}$ under nitrogen to prevent methemoglobin formation and degradation of the enzyme.

\section{Measurement of tyrosinase activity}

Tyrosinase activity was tracked by monitoring the rate of production of enzymatic products at $300 \mathrm{~nm}$ as described by Sigma. This method is based on the one developed by Duckworth and Coleman [21].

1. A reaction cocktail containing $0.34 \mathrm{mM}$ L-tyrosine and $12.8 \mathrm{mM}$ Potassium phosphate buffer with a $\mathrm{pH}$ of 6.5 was prepared.

2. This solution was oxygenated by bubbling oxygen through for 10 minutes.

3. 10 to $100 \mu \mathrm{L}$ of sample was transferred into a cuvette containing $2.9 \mathrm{ml}$ of the reaction mix and the absorbance at $300 \mathrm{~nm}$ was monitored. At this wavelength, only the enzymatic product of tyrosinase had a significant absorbance. There was no significant absorbance shown by other substances present in the reaction cocktail. Furthermore, addition of plasma, poly-hemoglobin and nanocapsules did not affect the enzyme assay. Under these conditions, one unit of enzyme activity was defined as the amount of enzymes which causes a maximum absorbance increase of 0.001 per minute at $300 \mathrm{~nm}$.

\section{Observation of the nanocapsules}

Scanning electron microscopy (SEM): The nanocapsules were diluted 4 times in distilled water. A drop of the solution was placed on a SEM holder and air dried. The holder was then coated for two minutes at $10 \mathrm{~mA}$ with a layer of gold (Polaron Au Sputter Coater, Polaron Instruments, Watford, UK). The samples were observed with a Hitachi S-4700 Field Emission SEM (Hitachi High-Technologies Canada, Inc., Rexdale, Ontario,) with the acquisition software quartz PCI (Hitachi).

Transmission electron microscopy (TEM): A drop of the nanocapsule solution was placed on a 200 mesh carbon-coated copper grid. Some of the grids were negatively stained with a solution of $3 \%$ phosphotungstic acid. The grids were examined and photographed with a JEOL JEM-2000FX microscope (Jeol Ltd., Tokyo, Japan) equipped with a Gatan (Pleasanton, CA, USA) 792 Bioscan 1k x 1k Wide Angle Multiscan CCD Camera.

Dynamic light scattering (DLS): Samples were diluted 8 to 80 times and filtered through $0.45 \mu \mathrm{m}$ syringe filters. DLS observations were carried out with a High Performance Particle Sizer (Malvern Instruments Ltd, Malvern, United Kingdom). Measurements were done in triplicates and the results were averaged. Dispersion Technology software 4.20 (provided with the particle sizer) was used for the data treatment.

\section{Results}

\section{Synthesis and characterization of PEG-PLA copolymer}

PEG-PLA block copolymer was prepared by heating MePEG (5kDa) and PLA $(6-16 \mathrm{kDa})$ to $180^{\circ} \mathrm{C}$ in the presence of the catalyst stannous-2-ethylhexanoate [20]. Stannous-2-ethylhexanoate is a powerful catalyst that is often used for the preparation of biological products because it has been approved by FDA as food additive [17].

Figure 2 shows a typical NMR scan of the copolymer. The peak at $\delta=5.2 \mathrm{ppm}$ (a) comes from one proton of each PLA monomer. The peak at $\delta=3.6 \mathrm{ppm}$ (b) represents the 4 protons of each ether PEG monomer. The 3 protons of the methyl group of each PLA monomer are responsible for the peak at $\delta=1.6 \mathrm{ppm}$ (c). The results of the TGA measurements in Figure 2 show that the copolymer begins its degradation at a temperature of about $200^{\circ} \mathrm{C}$. The DSC thermogram ( $\mathrm{G}$ of the copolymer) shows a crystallisation (exotherm) and a melting (endotherm). The onset crystallisation temperature $(\mathrm{Tc})$ is $5.9^{\circ} \mathrm{C}$ and the onset melting temperature $(\mathrm{Tm})$ is $42.8^{\circ} \mathrm{C}$.

\section{Physical characteristics}

Tyrosinase nanocapsules were observed by Scanning Electron Microscopy (SEM). The images show spherical and unaggregated nanocapsules. The small irregularities in the shape of the nanocapsules can be explained by the drying process. When observed by transmission electron microscopy (TEM) Polyhemoglobin-tyrosinase nanocapsules are spherical and without aggregation (Figures 3a,b,c,d). In Figure 3a, we can see the typical halo around the nanocapsules observed with negative staining. It is due to the PEG corona. The TEM images give a good idea of the size distribution of the nanocapsules.

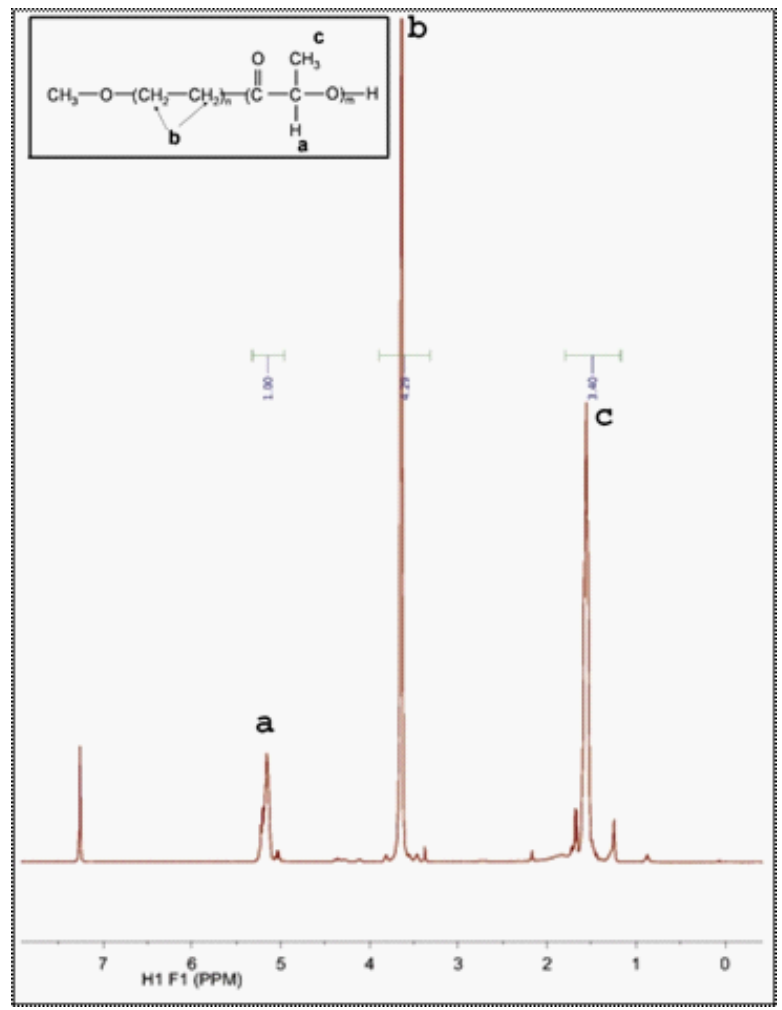

Figure 2a: ${ }^{1} \mathrm{H}-\mathrm{NMR}$ spectrum of the PEG-PLA (5-11K) block copolymer. 
Citation: Fustier C, Chang TMS (2012) PEG-PLA Nanocapsules Containing a Nanobiotechnological Complex of Polyhemoglobin-Tyrosinase for the Depletion of Tyrosine in Melanoma: Preparation and In Vitro Characterisation. J Nanomedic Biotherapeu Discover 2:103. doi:10.4172/2155983X.1000103

Page 4 of 9

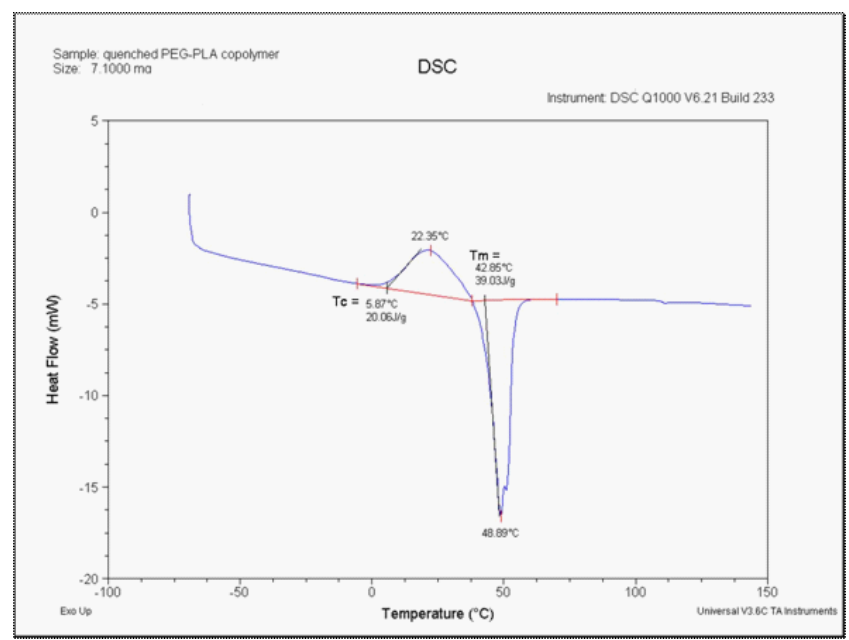

Figure $\mathbf{2 b}$ : DSC thermogram of the copolymer after quenching.
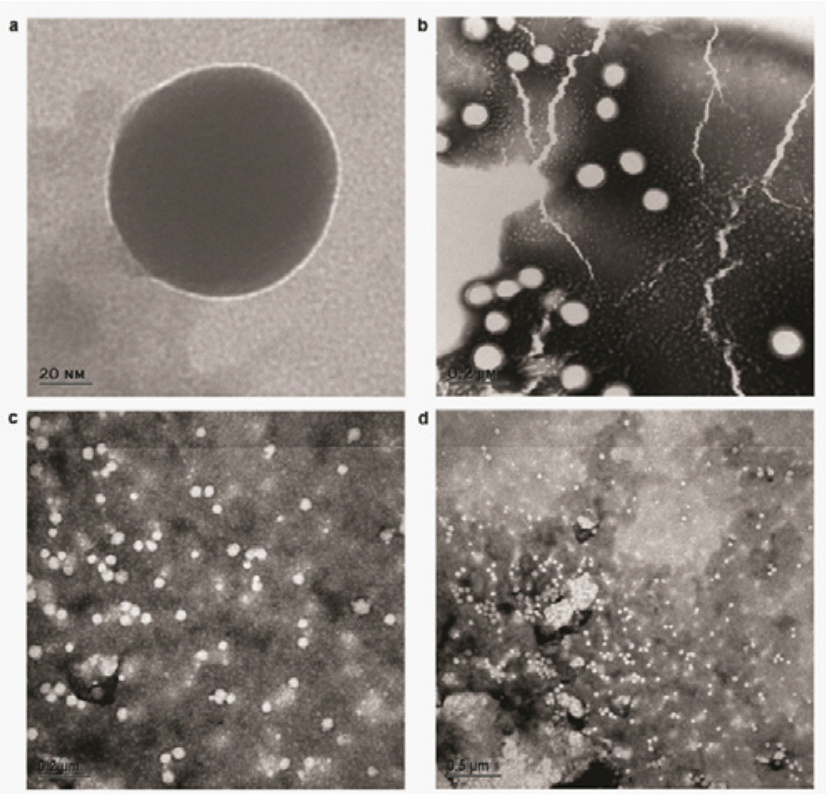

Figure 3: Observation of the nanocapsules with a Transmission Electron Microscope.

a, TEM image of one nanocapsule observed without negative staining. b,c,d, Dispersions of nanocapsules with negative staining observed at different magnifications with TEM

Figure 4 is a typical size distribution by intensity observed with Dynamic Light Scattering. The Z-average diameter for this population of nanocapsules is $65.2 \pm 0.5 \mathrm{~nm}$ (mean \pm SEM for 3 measures). The polydispersity index is $0.262 \pm 0.002$. We use Malvern's computer analysis for an estimation of the size distribution by volume (Figure 4).

\section{Control of the diameters of nanocapsules}

Since the size of the nanocapsules has a significant influence on their biodistribution and circulation time in blood, it is important to be able to control it. The speed of the magnetic stirrer is a critical parameter (Figure 5). The lower the speed, the largr the mean diameter.
This is consistent with the preparation method by emulsification [11,13]. A Therm-o-swirl stirrer from Precision Scientific was used for this experiment. Each measure is the mean of the Z-average diameter of 3 different preparations of nanocapsules. The error bars represent Standard Error of the Mean. The difference between a stirring speed of 4.5 and a stirring speed of 6 is statistically significant $(P=0,029$ with a Student's t-test). The difference between a stirring speed of 6 and a stirring speed of 7.5 is also statically significant $(\mathrm{P}=0,009)$.

\section{Effects of the size of PLA block in the copolymer}

The size of the PLA block in the copolymer also has a significant influence on the diameters of the nanocapsules. Two copolymers: $(6-16 \mathrm{k})$ and $(15-25 \mathrm{kDa})$ were used to prepare different batches of nanocapsules. The nanocapsules with the smaller copolymer (6-16k) had a Z-average diameter of $69.6 \pm 1.4 \mathrm{~nm}$ (Z-average \pm Standard error of the mean for 3 samples). The nanocapsules with the larger copolymer (5k, 15-25k) had a significantly higher Z-average diameter of $74.4 \pm 1.4$ $\mathrm{nm}$ (p-value with a student t-test $=0.034)$.

\section{Tyrosinase activity of the nanocapsules}

The enzyme activities were carefully followed at each step of the preparative procedure. After crosslinking with hemoglobin, tyrosinase retained $91.5 \pm 0.5 \%$ of its activity. After the encapsulation step, 74.5 $\pm 2.9 \%$ of tyrosinase activity was detected. The $25.5 \%$ missing are due to inactivation during encapsulation and/or restriction of tyrosine diffusion through the membrane since diffusion of tyrosine across the nanocapsules membrane is slower than free diffusion. Even if it is the case, the $74.5 \%$ of activity shows that polyhemoglobin-tyrosinase inside the PEG-PLA retains much of its ability to remove tyrosine.

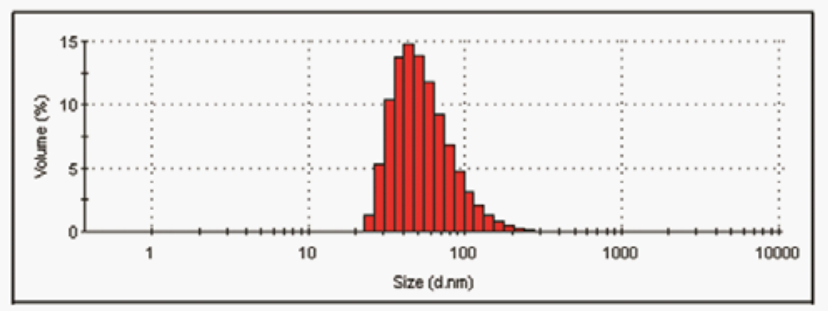

Figure 4: Observation of the nanocapsules by Dynamic Light Scattering. Size distribution by volume estimated with the Malvern software for the same observation.

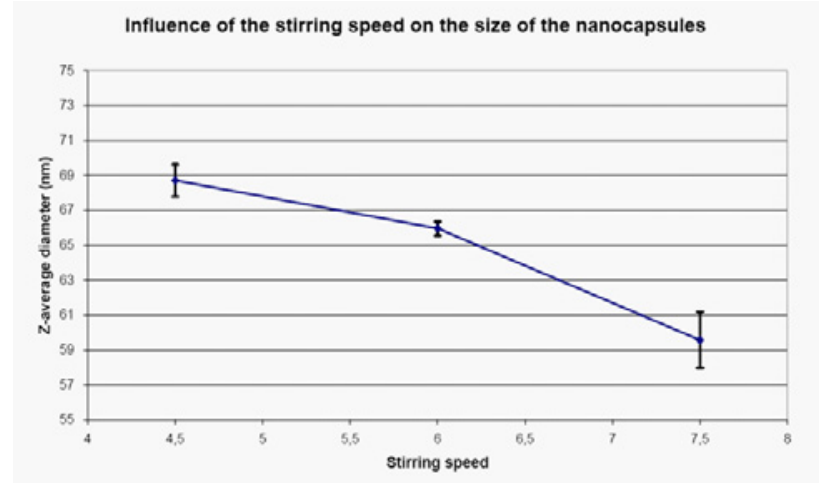

Figure5: Effects of stirring speed on average diameter measured by Dynamic Light Scattering. 
Citation: Fustier C, Chang TMS (2012) PEG-PLA Nanocapsules Containing a Nanobiotechnological Complex of Polyhemoglobin-Tyrosinase for the Depletion of Tyrosine in Melanoma: Preparation and In Vitro Characterisation. J Nanomedic Biotherapeu Discover 2:103. doi:10.4172/2155983X.1000103

Page 5 of 9

\section{Stability of the enzymatic properties of the nanocapsules}

Figure 6 shows that tyrosinase is stable when stored at $4^{\circ} \mathrm{C}$. For intravenous injection it is important to know the enzymatic stability at a body temperature of $37^{\circ} \mathrm{C}$. The activity of tyrosinase at $37^{\circ} \mathrm{C}$ was first tested in detailed over 8 hours. The results show that the tyrosinase activity of free tyrosinase decreases very quickly at $37^{\circ} \mathrm{C}$ reaching near zero after 8 hours (Figure 6a). On the other hand, nanoencapsulated polyhemoglobin-tyrosinase retains over $80 \%$ of the initial activity for 8 hours (Figure 6b). Polyhemoglobin-tyrosinase nanocapsules still retains $45 \%$ of its enzyme activity after 24 hours and more than $30 \%$ after 48 hours (Figure $6 \mathrm{c}$ ). Thus, this is within the therapeutic time range of 48 hours.

\section{Preliminary animal studies}

Wistar rats (270-280g) were obtained from Charles River Canada (St Constant, Québec).

The rats were anaesthetized with intraperitoneal injection of 55 $\mathrm{mg} / \mathrm{kg}$ of body weight sodium pentobarbital (CEVA santé animale, La Ballastière, France). The femoral vein and artery were isolated
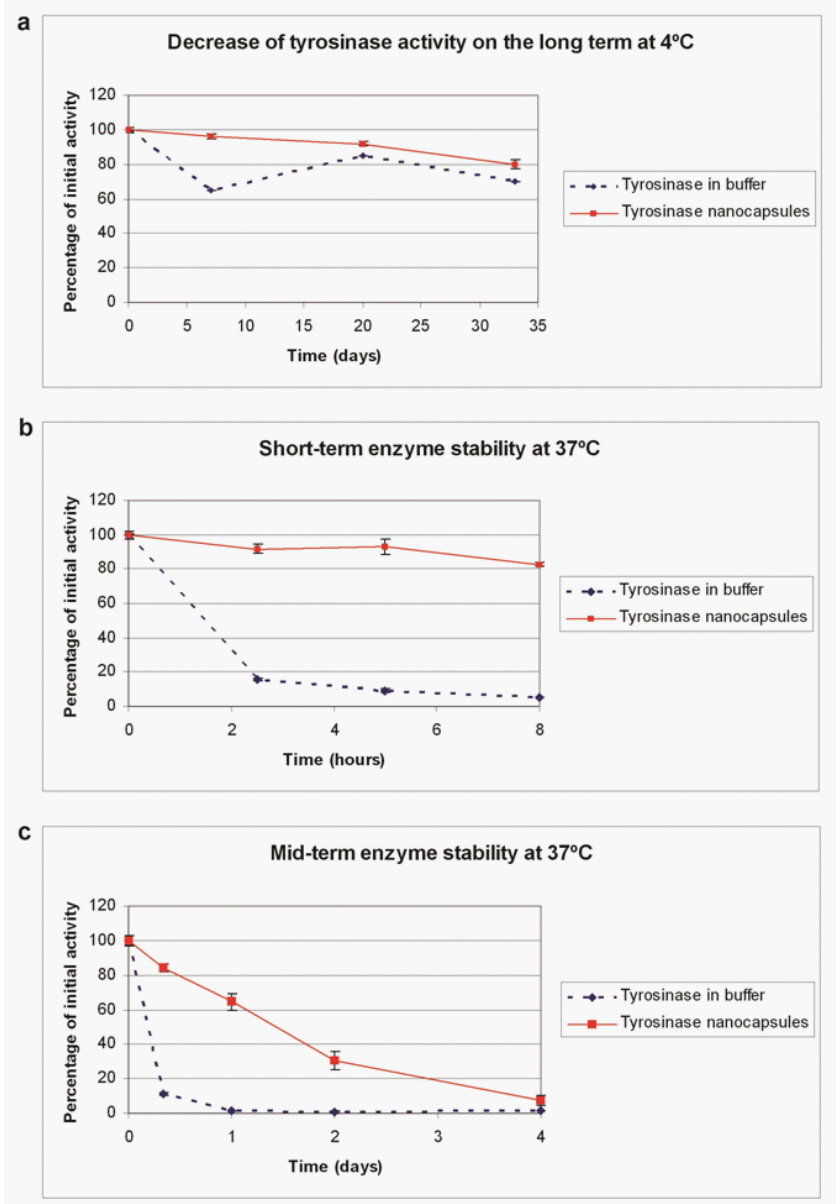

Figure6: Enzyme stability at different temperature. (a) Enzyme retains good stability at a storage temperature of $4^{\circ} \mathrm{C}$ (b and $\mathrm{c}$ ) At body temperature of 37 ${ }^{\circ} \mathrm{C}$ free tyrosinase activity decreases very quickly $16 \%$ after only 2.5 hours. On the other hand, the activity of nanoencapsulated tyrosinase retained over $80 \%$ of the initial activity for at least 8 hours and it is still $64.5 \%$ after 24 hours and $30 \%$ after 48 hours - within the therapeutic time range of 48 hours. and cannulated. A blood sample was taken from the artery. Each rat received $1.5 \mathrm{ml}$ of the PolyHb-tyrosinase nanocapsule suspension; PolyHb-tyrosinase or saline. Arterial blood samples were taken from the femoral artery 5 minutes after the injection, and then every hour, while the rat was kept under general anaesthesia. The samples were collected in heparinized tubes. They were immediately centrifuged at $750 \mathrm{rpm}$ for 10 minutes (EBA 12 centrifuge, Hettich Zentrifugen, Tuttlingen, Germany) to separate the red blood cells from the plasma and the nanocapsules. This speed was chosen because it is the speed at which a maximum of plasma can be recovered without removing the nanocapsules from the plasma. At the end of the experiment, the rat was euthanized with pentobarbital. $99 \%$ of the PolyHb-tyrosinase nanocapsules are still in circulation after five minutes. The tyrosinase activity in plasma was also measured. Five minutes after injection, tyrosinase activity in plasma for the rats that received the nanocapsules was $80 / 78 \%$ of the expected activity. It was only $71 \%$ of the expected activity for the rats that received PolyHb-tyrosinase. No activity was detected in the plasma of the rats that received an injection of saline. Within 5 minutes, plasma tyrosine levels fell to $10-13 \%$ of the initial levels for the rats that received nanoencapsulated PolyHb-tyrosinase. The tyrosine levels were maintained under $16 \%$ of the initial levels for the entire duration of the study ( 4 - 5 hours)). For the rats that received PolyHb-tyrosinase, plasma tyrosine levels fell to $14 \%$ of the initial levels within 5 minutes and maintained under $22 \%$ for the duration of the study.

\section{Discussion}

This study describes the preparation and in vitro characterization of nanodimension biodegradable artificial cells nanoencapsulating polyhemoglobin-tyrosinase. The aim is to use this for the lowering of systemic tyrosine needed for the growth of melanoma, a fatal skin cancer that at present has no effective treatment [1-3]. A poly (ethylene glycol)-poly (lactic acid) block-copolymer (PEG-PLA) was first prepared and characterized using H-NMR spectrum and DSC thermogram. This block-copolymer was used for the optimization of preparing PEG-PLA tyrosinase nanocapsules. Studies using transmission electron microscopic and scanning electron microscopic studies show round and non-aggregated nanocapsules with a PEG halo around each nanocapsule. Using Dynamic Light Scattering, the Z-average diameter is $65.2 \pm 0.5 \mathrm{~nm}$ (mean \pm SEM for 3 measures) and the polydispersity index is $0.262 \pm 0.002$. The mean diameter can be controlled by the stirring speed of the reaction mixture or the size of the PLA block in the copolymer. After the encapsulation step, $74.5 \pm 2.9$ $\%$ of tyrosinase activity was recovered. This is a marked improvement from the standard method of nanoencapsulating proteins and enzymes [15-18]. At the body temperature of $37^{\circ} \mathrm{C}$, free tyrosinase lost all its enzyme activity after 8 hours. On the other hand, Polyhemoglobintyrosinase nanocapsules retained $80 \%$ of the initial activity after 8 hours, $45 \%$ after 24 hours and 30\% after 48 hours. 30\% of the initial activity is sufficient for lowering systemic tyrosine. This increase in stability compared to the free enzyme at $37^{\circ} \mathrm{C}$ is because of the use of polyhemoglobin-tyrosinase. Our group has showed in earlier studies that enzyme stability at body temperature can be markedly increase by the use of polyhemoglobin-enzyme complex $[8,9,12,13]$. Increase in enzyme stability during the preparation and also the increase in enzyme stability at the body temperature of $37^{\circ} \mathrm{C}$ are important in its therapeutic use for lowering systemic tyrosine for melanoma. In the next step of testing this in a melanoma mice model, one has to consider the safety aspects. In this regard, Liu and Chang [22,23] have recently injected intravenously PEG-PLA polyhemoglobin nanocapsules of 
Citation: Fustier C, Chang TMS (2012) PEG-PLA Nanocapsules Containing a Nanobiotechnological Complex of Polyhemoglobin-Tyrosinase for the Depletion of Tyrosine in Melanoma: Preparation and In Vitro Characterisation. J Nanomedic Biotherapeu Discover 2:103. doi:10.4172/2155983X.1000103

Page 6 of 9

$1 / 3$ the total blood volume in rats. They reported no short term nor long term adverse effect either in the general condition or in systemic biochemistry or in the histology of kidney, liver and spleen [22,23]. Most important of all is that there is no retention of the nanocapsules in the liver or histological changes in the liver histology. Earlier study using polyhemoglobin-tyrosinase already shows that there is no adverse effect from the sustained lowering of the systemic tyrosine level over a 19 day period [9]. Furthermore, this is effective in retarding the growth of the melanoma in the mice [9]. The problem with the use of polyhemoglobin-tyrosinase is the need for daily intravenous injection since it is removed too quickly after infusion. Nanodimension PEGPLA artificial cell encapsulated polyhemoglobin-enzyme can remain in the circulation for a much longer time after intravenous injection when compared to polyhemoglobin-enzyme [20]. Preliminary result in rats shows that 1 intravenous injection of PEG-PLA nanocapsules containing polyhemoglobin-tyrosinase lowers the systemic tyrosine level to $10-13 \%$ after 5 minutes. A low level of under $16 \%$ is maintained for the duration of the present study of 4-5 hours. Thus, we are now ready to go into the next step of studying the effect of these tyrosinase nanocapsules to lower systemic tyrosine for the treatment of melanoma.

\section{Acknowledgements}

TMSC acknowledges the operating term grant from the Canadian Institutes of Health Research. CF acknowledges scholarships support from Ecole Polytechnique in France and its Alumni association and from McGill University.

\section{References}

1. Borden E (2002) Melanoma : Biologically Targeted Therapeutics. Humana Press, Totowa, NJ 389.

2. Gray-Schopfer V, Wellbrock C, Marais R (2007) Melanoma biology and new targeted therapy. Nature 445: 851-857.

3. Meadows GG, Pierson HF, Abdallah RM, Desai PR (1982) Dietary influence of tyrosine and phenylalanine on the response of B16 melanoma to carbidopalevodopa methyl ester chemotherapy. Cancer Res 42: 3056-3063.

4. Meadows GG, DiGiovanni J, Minor L, Elmer GW (1976) Some biological properties and an in vivo evaluation of tyrosine phenol-lyase on growth of B-16 melanoma. Cancer Res 36: 167-171.

5. Chang TM (1964) Semipermeable Microcapsules. Science 146: 524-525.

6. Chang TM (1971) Stabilisation of enzymes by microencapsulation with a concentrated protein solution or by microencapsulation followed by crosslinking with glutaraldehyde. Biochem Biophys Res Commun 44: 1531-1536.

7. D'Agnillo F, Chang TM (1998) Polyhemoglobin-superoxide dismutase-catalase as a blood substitute with antioxidant properties. Nature Biotechnology 6: 667 671

8. Chang TM (2008) Nanobiotechnological modification of hemoglobin and enzymes from this laboratory. Biochimica et Biophysica Acta: proteins \& Proteomics 1784: 1435-144.

9. Yu B, Chang TM (2004) In vitro and in vivo effects of polyhaemoglobintyrosinase on murine B16F10 melanoma. Melanoma Res 14: 197-202.

10. Chang TM, Poznansky MJ (1968) Semipermeable microcapsules containing catalase for enzyme replacement in acatalasaemic mice. Nature 218: 243-245.

11. Chang TMS (1972) monograph on Artificial cells. Springfield.

12. Chang TM (2005) Therapeutic applications of polymeric artificial cells. Nat Rev Drug Discov 4: 221-235.

13. Chang TM (2007) Monograph on "ARTIFICIAL CELLS: biotechnology, nanotechnology, blood substitutes, regenerative medicine, bioencapsulation, cell/stem cell therapy".

14. Chang TM (1976) Biodegradable semipermeable microcapsules containing enzymes, hormones, vaccines, and other biologicals. J Bioeng 1: 25-32.

15. Avgoustakis K (2004) Pegylated poly(lactide) and poly(lactide-co-glycolide) nanoparticles: preparation, properties and possible applications in drug delivery. Curr Drug Deliv 1: 321-333.

16. Sah $H$ (1999) Protein behavior at the water/methylene chloride interface. $J$ Pharm Sci 88: 1320-1325

17. Zambaux MF, Bonneaux F, Gref R, Dellacherie E, Vigneron C (2001) Protein C-loaded monomethoxypoly (ethylene oxide)-poly(lactic acid) nanoparticles. Int J Pharm 212: 1-9

18. Tobio M, Gref R, Sanchez A, Langer R, Alonso MJ (1998) Stealth PLA-PEG nanoparticles as protein carriers for nasal administration. Pharm Res 15: 270275

19. Yu WP, Chang TM (1994) Submicron biodegradable polymer membrane hemoglobin nanocapsules as potential blood substitutes: A preliminary report Artif Cells Blood Substit Immobil Biotechnol 22: 889-894.

20. Chang TM, Powanda D, Yu WP (2003) Analysis of polyethylene-glycolpolylactide nano-dimension artificial red blood cells in maintaining systemic hemoglobin levels and prevention of methemoglobin formation. Artif Cells Blood Substit Immobil Biotechnol 31: 231-247.

21. Duckworth HW, Coleman JE (1970) Physicochemical and kinetic properties of mushroom tyrosinase. J Biol Chem 245: 1613-1625.

22. Liu ZC, Chang TM (2008) Effect of PEG-PLA-nano artificial cells containing hemoglobin on kidney function and renal histology in rats. Artificial Cells, Blood Substit Immobli Biotechnol 36: 421-430.

23. Liu ZC, Chang TM (2008) Long term effects on the histology and function of livers and spleens in rats after $33 \%$ toploading of PEG-PLA-nano artificial red blood cells. Artif Cells Blood Substit immobil Biotechnol 36: 513-524. 